\title{
Design of a Self-standing Multimedia Enriched Projector to enhance teaching experience in classroom in Brazilian public schools
}

\author{
Alex Sandro Gomes \\ CIn - UFPE \\ Rua Prof. Luis Freire, \\ $\mathrm{s} / \mathrm{n}-50.740-560$ \\ Recife PE Brasil \\ asg@cin.ufpe.br
Leonardo Castillo
Departamento de
Design - UFPE
Av. da Arquitetura,
s/n 50740-550
Recife, PE.
leonardo.castillo@uf
pe.br

\author{
Aline Timóteo \\ CIn - UFPE \\ Rua Prof. Luis Freire, \\ s/n 50.740-560 \\ Recife PE Brasil \\ alt@cin.ufpe.br
}

\author{
Claudia R.A. Gomes \\ DE - UFRPE \\ R. Manoel de \\ Medeiros, $\mathrm{s} / \mathrm{n}$ Dois \\ Irmãos 52171-030 - \\ Recife, PE - Brasil \\ cra@ded.ufrpe.br
}

\author{
Victor Wanderley \\ CIn - UFPE \\ Rua Prof. Luis Freire, \\ s/n 50.740-560 \\ Recife PE Brasil \\ vwcm@cin.ufpe.br
}

\section{Sônia Sette}

NEAD - UFPE

\author{
Tiago Machado \\ CIn - UFPE \\ Rua Prof. Luis Freire, \\ s/n 50.740-560 \\ Recife PE Brasil \\ tlam@cin.ufpe.br
}

\section{Célia Fortes}

In memoriam

\author{
Manoel E. de Lima \\ CIn - UFPE \\ Rua Prof. Luis Freire, \\ s/n 50.740-560 \\ Recife PE Brasil \\ mel@cin.ufpe.br
}

\begin{abstract}
Resumo Há muitas décadas as políticas públicas promovem o uso de tecnologias educacionais em sala de aula no Brasil. Alguns resultados do impacto no desempenho dos alunos são notados. Neste artigo apresentamos os processos de design e avaliação de um projetor multimídia com sistema operacional livre embarcado para o compartilhamento de conteúdo em sala de aula. Empregamos um processo de design participativo baseado no provimento de apoio ao professor proporcionar um maior engajamento dos alunos. Ao longo do processo concebemos padrões do processo de design do sistema operacional e do hardware. Essa abordagem de projeto foi desenvolvida em escola pública no Brasil. Discutimos neste artigo essa experiência e exploramos as implicações para a prática docente.
\end{abstract}

Palavras-Chave: Melhoria da prática de sala de aula, mídia na educação, Interação humano computador, desenvolvimento especifico de um país

\begin{abstract}
For many decades, public policies promoted educational technologies usage in classroom in Brazil. Some results related to the impact on student's performance have been noticed. We present a design and evaluation of an educational sharing multimedia platform that provides facilities for teachers in the classroom. We employed a participatory design process based on providing support intended to help teachers engage in the classroom context. We could elicit a list of design guidelines for the specific operational system and a hardware case. This design approach has been developed to empower teachers in public schools in Brazil. We discuss our experience with this initiative and explore its implications for teaching.
\end{abstract}

Keywords: Improving classroom teaching; media in education; human-computer interaction; country-specific developments

Recebido: 04 de Abril de 2013 / Aceito: 25 Junho de 2013

DOI: 10.5753/RBIE.2013.21.01.23 


\section{Introduction}

In the last decades, teachers introduced many kinds of devices in their professional practice in classroom. Since the beginning of the PC era, teacher experience has used computing for simulating, data collecting and analysis, searching for information and mainly presenting media. In the same period, the international literature on teaching with technology has documented a series of difficulties involving the usage of electronic devices, and a certain level of refraction to this introduction in the teaching practices [8, 14]. The reasons are related to the consecutive complexity of main tasks when using those devices. The introduction of electronic devices increases enormously the complexity of teaching practice, especially when planning and lecturing in classroom. From a distinct perspective, the usage of modern media resources has significant impact on children literacy in the first school years in the world. Computer software and tangible interfaces can help engage pupils in effective learning activities. Presenting concepts in different medias enriches the learning experiences and is well accepted by pupils.

However, these resources such as Internet, educational software and games, among others, when well applied, are able to provide an interesting, stimulating and playful learning environment, with the potential to motivate students to learn. In a school, where the priority is reproduction of knowledge and welfare, such resources represent an important support to the construction of a space for knowledge, an area of real interactivity, where students and teachers can discuss their points of view, update and contextualize information, build consensus and cooperate to expand their understanding of facts, ideas and concepts.

In this context, interactive systems are being increasingly requested by educators who want to keep their students in contact almost daily with new technologies. These systems bring to the classroom the possibility to create tests, to play electronic games, etc. allowing students to interact in real time with the environment, and also answering questions, dynamically made by the system itself or the teacher, and so on.

A widespread device in Europe and North America, the electronic whiteboard focuses on presentation and content building. The images generated by computers are shown in the board through a digital projector, where they can be viewed and manipulated on the screen. Thus, teachers and students who are making use of the tool, for example, can add annotations to text, draw, highlight information in a Web page, exploring the concept of authorial production in the classroom.
Several companies have offered solutions associated to this technological concept, such as $3 \mathrm{M} \AA[01]$, Panasonic ® [27], Polyvision [28] and SMART Technology ${ }^{\circledR}$, which appear as leaders in this segment, with various types of solutions for electronic boards.

In Brazil, companies offer solutions based on educational tables, as concrete didactic materials for children to interact with the personal computer. The activities associated with these tables are related to several knowledge areas and stimulate motor skills development, visual perception and logical reasoning. Activities are structured according to students' age and level.

Although these systems are undoubtedly learning tools that provide the teacher a dynamic and constructive teaching environment, they are not self-contained. In fact, there is a need of a computer for information processing, as well as a multimedia device for external projection, so that everyone can follow the development of the activities in the classroom.

In Brazilian public schools, the electronic devices are restricted to desktop PCs arranged in special classrooms, where students and teacher access educational applications and context. To improve such approach, the Ministry of Education has promoted the design and dissemination of a wide range of educational media in the last years. Particularly, two years ago, this Ministry demanded the design of an electronic PC platform designed to simplify multiple aspects of the teaching practices with a wide range of educational media. This work presents in details the design of a multimedia device, created to meet this need, named Lampejo.

\section{Design Process}

When commissioned by the Ministry of Education [03], this electronic PC platform, called Lampejo, was an attempt to give support to the multiple aspects of the teaching practices inside the classroom, through the use of a portable, easy-to-use, and low-cost efficient multimedia device. In order to reach that objective, the development process was based on the results of a qualitative field research made in Recife, Brazil. We were oriented by a social constructivist framework in our design decisions [04] perceiving reflexive acting and social interaction as part of the origins of human development.

The development team adopted a user-centered design approach consisting of seven iterative phases: briefing, problem understanding, ideation, prototyping, selection, 
implementation, and testing [17]. One of the main characteristics of this design method is that along the development process, those steps are not linear; they occur simultaneously and can be repeated as many times as necessary. Therefore, each stage is developed in an iterative and incremental way, making use of specific tools and techniques that help gathering useful information and feedback from users for the advance of a consistent design solution [34].

\subsection{Problem understanding}

The process began with briefing definition. The project's briefing consisted of a short description of what the device should accomplish: an open-source approach, portable, easy-to-use, and low-cost platform capable of multimedia processing, screen projection, and internet connectivity for collaborative work development at school.

The next step was to gain a clear understanding of the context of use for the intended device. Using ethnographic interviews [7] the team visited public schools and conducted qualitative data gathering through immersive observations, photo and video footage, and semi-structured interviews with teachers, coordinators, and directors. 25 teachers and directors from two public schools, as well as 5 specialists in education participated in the process.

The ethnographic approach helped the team to be aware of the constraints and possibilities of the use of computing technology within a public school context, where teachers normally don't have personal computers or laptops; most of the time, lessons are centered on what teachers can present on the blackboard and what the textbook guide them to do; and classrooms are equipped with obsolete school furniture, like tables, chairs, and blackboards. Under the circumstances, it was difficult to imagine a radical scenario transformation in terms of electronic devices usage. At this point, it seemed to be necessary an intermediary solution that improves the way teachers present context and mediate learning, considering in the design process aspects like:

- The knowledge level and degree of proficiency of teachers using technology. Teacher's knowledge level and experience of technology is quite variable;

- The structures of activities that teachers develop in classroom in order to provide dynamic context to the content presented in class. Some of these dynamics were analyzed during this project to improve the understanding of needs in the teaching environment;

- The most used technologies in the classroom and their degree of importance from the teachers' point of view.

Based on the material collected during the field observations and all the gathering procedures, such as questionnaires, discussion footage, teacher's interviews and photos of the school environment, it was possible to map some of the main aspects that led to the identification of the project requirements, as following:

\section{System's basic functionality:}

- Audio, images, and video recording and playback

- Videoconferencing

- $\quad$ Sound amplifying

- $\quad$ TV and radio signal reception

\section{Input and output systems:}

- Integrated projection system

- TV, DVI output

- Microphone input

- USB ports

- Bluetooth recognition

\section{Connectivity:}

- Access to web content

- Internet connectivity for collaborative work development

- On line construction of documents, worksheets and presentations

- Access to materials repository

Accessibility:

- User-center design

- Audio navigation

- Interface Personalization and configuration

- Minimal use of mouse

\section{Desired functional requirements:}

- Digital TV reception

- Multidirectional screen projection

- Illuminated keyboard

- Universal Access

- Networking with other school devices

\section{Non-functional requirements:}

- Design:

- Lightweight, compact, portable design 
- Heavy-duty performance

- Easy and low cost maintenance

Once data from ethnographic interviews was collected and feedback was properly compiled, the next step in the process was to identify teachers' and students' needs and goals, by using a scenario building technique [19]. Scenario building is a decision-making tool that brings together participants from all levels for the creation of a narrative that explores possible design alternatives and their implications, taking into account project's requirements and user's demands [05].
In order to map possible scenarios of use for the new device, we first produced a questionnaire to be answered by teachers and discussed during focus groups sessions. The collected data was used to construct a set of personas representing the diversity of observed users. Personas helped us visualize users' motivations, behaviors, attitudes, aptitudes, mental models, activity flows, environments, and frustrations, when they use computer products or systems in a specific context [40]. Finally, to facilitate the visualization of the narrative, the design team created a storyboard with all the personas and context of use defined during this phase (see Figure 1).

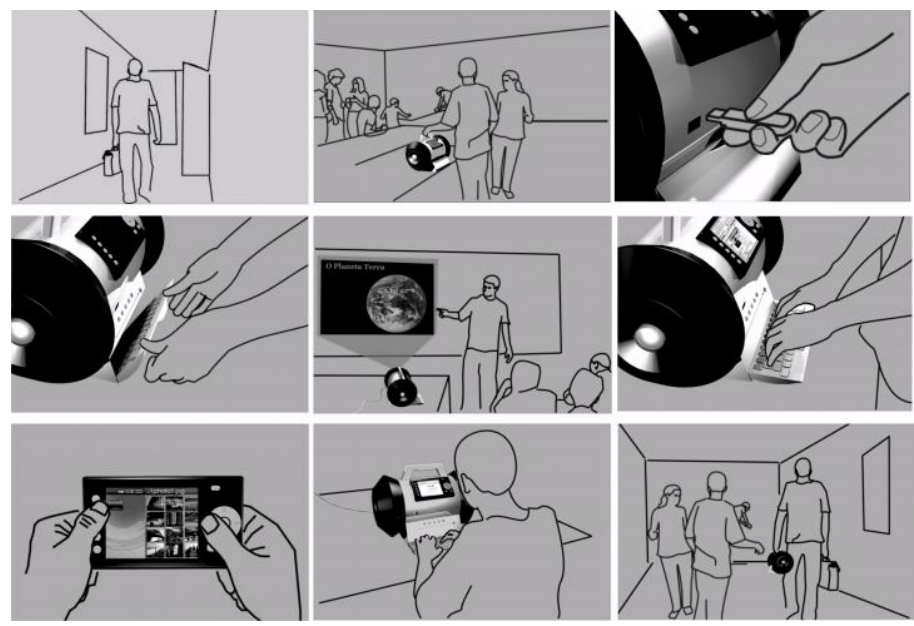

Figure 1 : Scenario building representation using storyboarding.

Along with scenario building, it was necessary to cluster possible technological trends that best suit the project's technical requirements identified during ethnographic interviews. Using mind-maps as a supporting tool [6], the team conducted a series of informal conversations with specialists from universities, such as pedagogues, psychologists and specialist in media technology, to get a better understanding of users and context involved in the learning process. This gave the team a complete picture of how computer and media technologies could support teaching practices in the classroom.

The output from this initial research phase was key to the ongoing project development efforts. At this point of the process, the design team had a clear understanding of users' goals and needs, as well as the technologies that could be used for the project. The construction of scenarios and mind-maps allowed the design team to advance into the first stages of the ideation phase.

\subsection{Ideation and prototyping}

Ideation was a key phase for the definition of the device's basic elements: functionality, form, and interface. At this point of the process, it was necessary to define a clear design concept that could meet the requirements defined in the previous phase. The interdisciplinary design team composed by teachers, education experts, electronic engineers, researchers in Computer Science and Design, gathered during a sixmonth period to guide the ideation process in weekly sessions of brainstorming and prototyping. It was a collaborative effort where a myriad of ideas was explored through the production of hundreds of sketches and storyboards as well as by the building of low-fidelity prototypes (see Figure 2).

- The conquer; and

- the channel. 


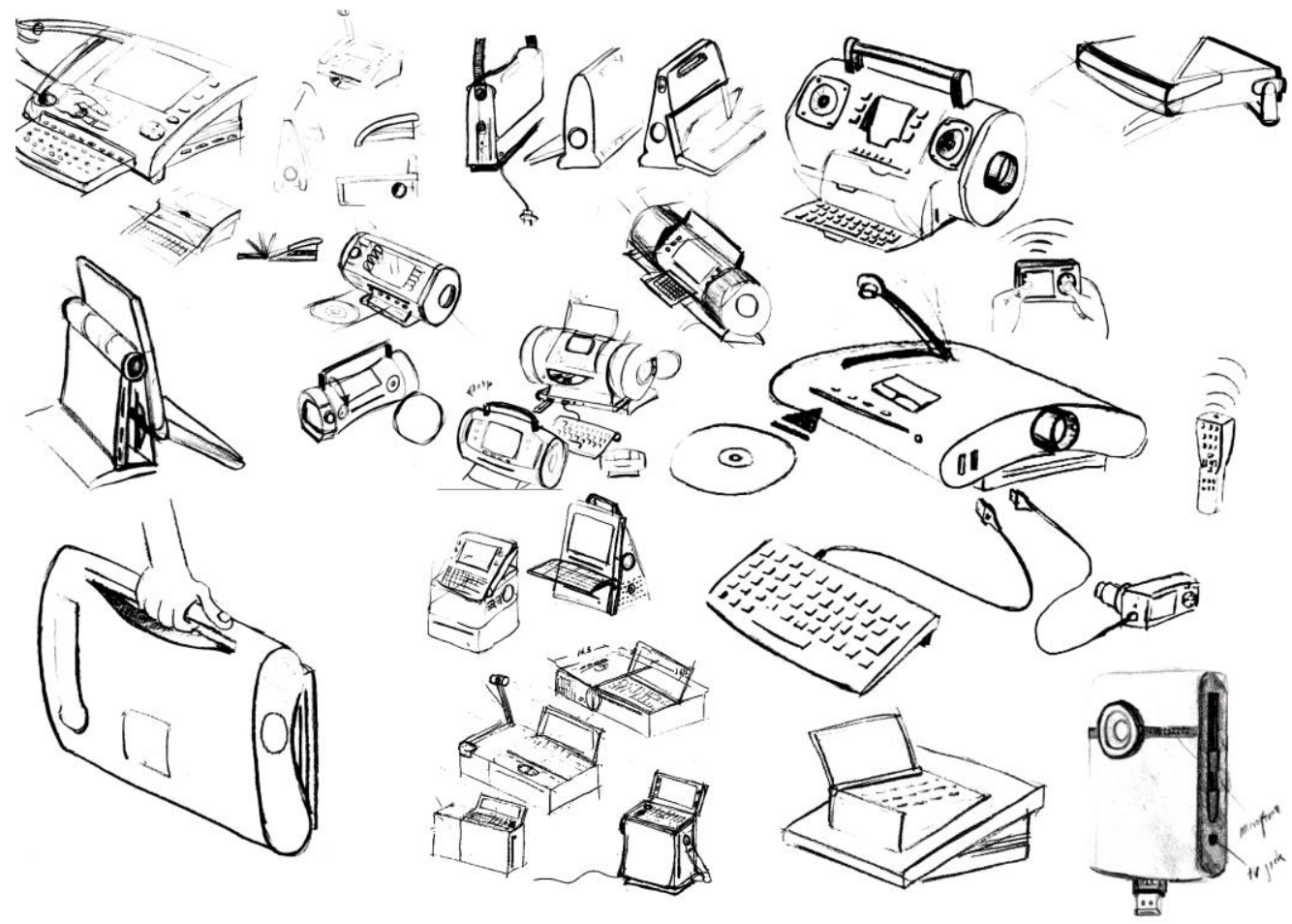

Figure 2: Initial ideas and concepts for Lampejo.

Once the basic characteristics of the device were defined and tested to some point using 2D representation techniques, such as sketches, drawings, and renderings, it was time for the building of a 3D prototype.

During early stages of prototyping, a series of paper mock-ups and low-fidelity prototypes was constructed, in order to explore and give concrete form to the device. The challenge was to conceive a device with a familiar look, to facilitate its acceptance among teachers. To this aim, the design team worked around metaphors inspired by familiar artifacts such as portable audio systems, or multimedia projectors for form definition, as in the case of a first prototype based on the morphology of a micro system, a familiar artifact frequently used by teachers and students at schools (see Figure 3).

In parallel with aesthetics definition, the development team also built a functional prototype, incorporating many of the system's electronic components together with the first version of the user interface. The resulting appliance was brought to schools to be informally tested and evaluated by teachers and students (see Figure 4). It was an opportunity to check the system reliability and functional performance of its components. It was also a chance to test the system's interface.

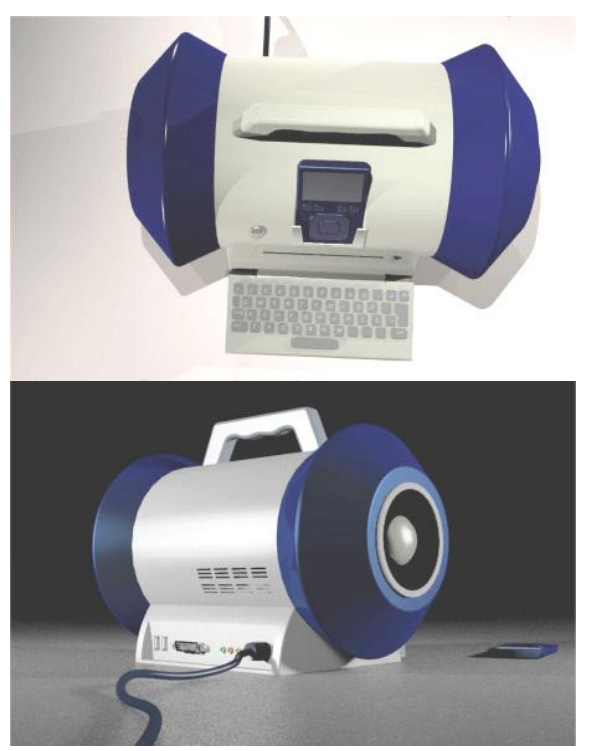

Figure 3: 3D prototype using a portable audio system as a metaphor. 


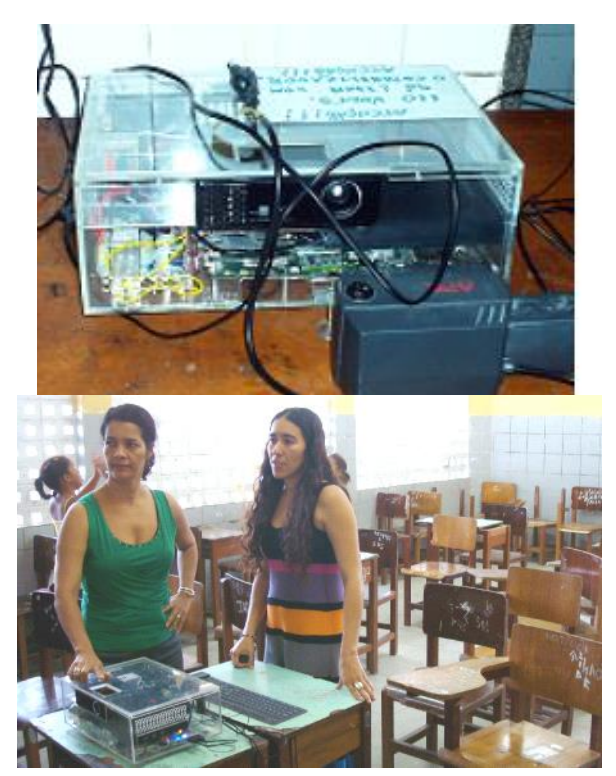

Figure 4: Testing of the functional prototype at the school.

These two prototyping approaches (aesthetical and functional) gave the design team a clear understanding of users interacting in a real context of use. It also served to test the technologies that best suited the device requirements. For instance, during testing in classrooms, overheating problems became apparent. This lead to a series of design modifications for better cooling options of the device that changed components internal distribution.

At the end of the first prototyping phase, a highfidelity (visual and functional) prototype was built, using rapid prototyping tooling [02] (see Figure 5). The final result allowed validating the device's look and feel, as well as its tangible interface and software platform.

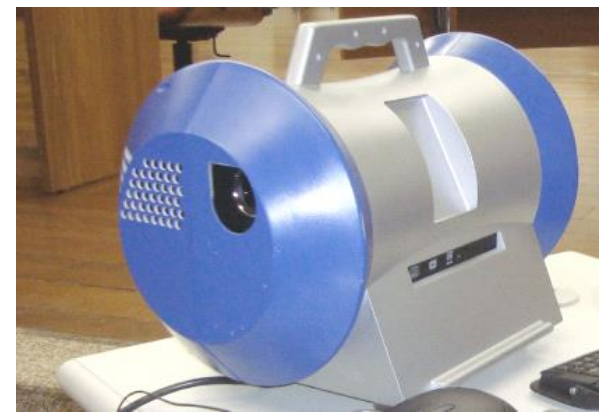

Figure 5: First high-fidelity prototype.

A second, high-fidelity prototype was then developed and constructed using the same rapid prototyping tools and processes (see Figure 6). As a result, such an evolved prototype matches the features set described in the briefing. The device was subject of more formal tests with students. The focus was on validating the tangible interface and the platform as a whole.

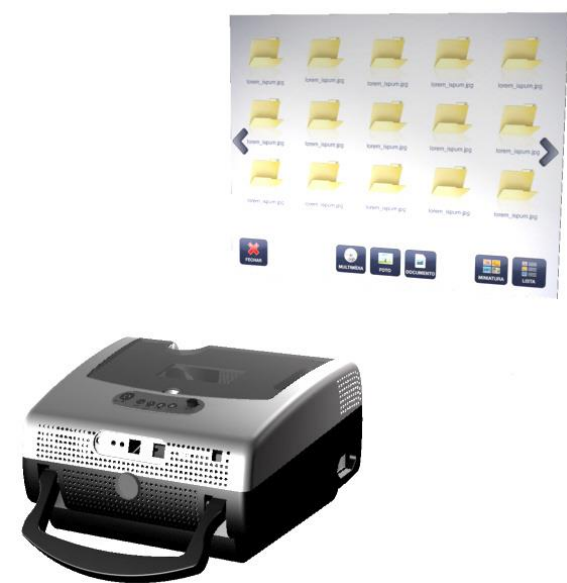

Figure 6: Second fully functional prototype.

\subsection{Functional testing}

Every time a functional prototype was built, it was taken to school to be used in its real context. The participants were eight teachers and theirs students in a public school. They were all volunteers. Even though students participate in all situations their tasks were not analyzed.

The result of these procedures resulted in the refinement of each prototype version. We could also finetune the equipment possibilities for the use in the teaching context. For instance, after interacting with the first high fidelity prototype, users rejected the proposal for two main reasons: Its "old fashioned" aesthetics, and because it presented difficulties for mobility. During the testing section, actions were observed, recorded and videotaped for a further task analysis. We pursued efficiency in usage and the results oriented the iterative evolution of the prototypes.

\subsection{Data gathering}

The data collected during interviews was analyzed using a dialogical approach, in three main stages. In the first one, the main points are introduced to the participants. Following, we conducted a locus observations focusing on the teachers' main actions and reaction with technology in the context of work. In the end, interviews with research subjects are registered and interpreted.

\subsection{Semi-structured interview}

This technique was utilized with three different groups: teachers, students and technical coordinators. The interview technique was used to gather teachers' qualitative impressions about ease-of-use of Lampejo, presented failures, future functionalities and class qualities improvements. Our aims with these interviewers was gathering data from a specialist with large 
knowledge about the educational process before and after the Lampejo adoption.

We coordinated two phases of qualitative research. In the first one, we interviewed students, teacher and technical coordinators about the usage and utility of Lampejo. In a second moment, a narrowed and accurate dialogical analysis was conducted on the teacher practices in the classroom.

We aimed at gathering information about the teachers' impressions after they practiced using Lampejo. The main focus of our interviews was: the ease to use of the system, the failures encountered, suggestions of future functionalities and how Lampejo improved the classes' quality. This technique has been used to identify how Lampejo could help teachers in their educational activities.

Among the students our aim was to understand how they could perceive this resource as part of the settings of their daily classes. Thus, we focus on identifying their opinions about gains in their own experience.

The technical coordinators were responsible for scheduling the use of Lampejo by the teachers. They participated as users in the periodical observations and interviews about the use of the prototype and its results.

\subsection{Observations}

The observation technique was used to identify how Lampejo works in its natural environment with teachers and students. At this stage, the non-participatory observation of the researcher would be held with the volunteer staff in its performance in the classroom, using educational software especially designed for research, mediated by Lampejo.

This procedure provides the analysis and understanding, the learning and mediation phenomena that permeate the classroom. In addition, recording the reactions, gestures, tone of voice, and other relevant aspects to the interpretation of teaching, as they conduct their pedagogical practices. All of this is put into action in their routine daily activities of the classroom with the use of Lampejo, giving meaning to the process of teaching and learning.

Some important development details not revealed in the interviews were registered during the observations. One of them was the necessity of a clear projection to avoid visualization conflicts occurred by blured walls and blackboards (see Figure 7).

\subsection{Qualitative data analyses and interpretations}

The purpose here was to describe the context of the classroom where teaching takes place, the vision of teaching and practice with computational artifacts and educational software. This focus was to understand how the new computational artifacts and educational software impacted the decision-making teachers falls in and the teaching practice structure.

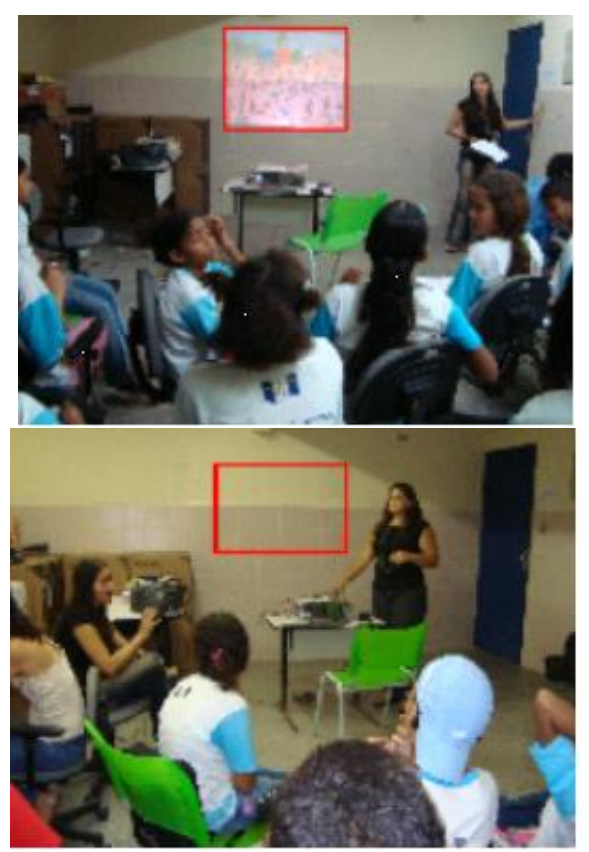

Figure 7: The division of the wall implies in the image exhibition, which influence the comprehension of students and the teacher's explanations.

The investigative process of this social and qualitative research with educators, seeks to know the meaning Lampejo could have when introduced in the practices of teachers in a computerized classroom. This strategy allows us to analyze their thoughts, choices and needs into IT knowledge area, mobilized in the context of teaching learning.

The methodological approach adopted in the research is a qualitative social research by allowing a better understanding of the phenomenon being studied, subjects being studied and their impressions in the educational context.

The collected data were transcribed with nVIVO [23], an auxiliary software tool for qualitative analyses purposes. We created free categories [10] according to our necessities, all of them reflected our impressions about usability failures, system requirements, productivity gains, future suggestions, product values and 
so on. All categories and the data of each one were presented to a team of the project leaders including software engineers, product designers, educators and usability specialists. After the presentation and the eventual considerations, the analyses were turned into a list of necessities and requirements.

\section{Results}

In this section we present our design and the qualitative evaluation results: task analysis and the dialogical analysis of impact on teachers' practice. In the next section we present the design of Lampejo. Then we present the results of task analysis and dialogical evaluations.

\subsection{Lampejo: the final conceptual model}

With the aforementioned procedures in mind, we have conceived Lampejo, (see Figure 8). It is a portable device with multimedia embedded that aggregates the functions of "projector, and intelligent display", low-cost, simpleto-use, and designed to fulfills the dynamics in a typical classroom usage. The combination of the functions of a projector system and computer allows to connection to the Internet, portability, manipulation of the multimedia content, collaborative task development, presentation of the educational content, as well as other functions. The device consists of three components: the base, the remote control and the operating system.
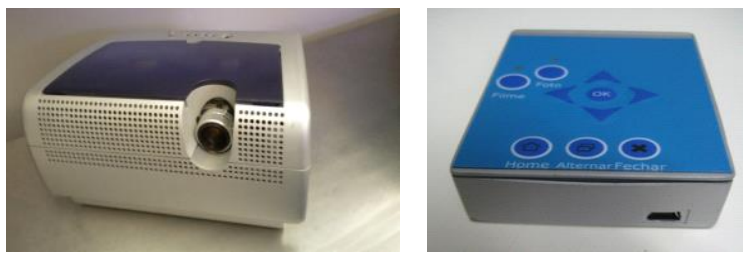

Figure 8: Base and remote control of Lampejo.

The base can be defined as the core of Lampejo. It contains the CPU and projector system. The remote control also manages the devices in the base. One of the major preoccupations of Lampejo development was the base design: it was decided that the design should be simple and intuitive and that the equipment should also be easy to carry and move around. Through the continuous interaction among developers and users it was possible to reach a design that was simple for users who are unfamiliar with technology.

The transportation problem was solved with the development of a specific carry bag for Lampejo, in which all the peripheral equipment could be packed and carried without difficulty by the user.

The remote control can communicate with the base via infrared technology, allowing the user to navigate the interface, open or close applications, navigate within applications. Finally, this device allows a greater interaction between the user and what is being projected. This control illustrates one of the main differentials of this proposal, because it allows the capture of images, videos and sounds, and interaction that makes possible a real interaction and collaboration among students, teachers and technology.

The operating system was prototyped using Flash. This language has been widely used in educational system development and enables the development of a friendly layout and easy integration with several media types. Besides the friendly interface, the system possesses the following characteristics:

- Encapsulation: in other words, the operating system is encapsulated so that the user cannot access it, reconfigure the system or generate situations that he does not know how to solve;

- Automatic configuration: the system should detect the internet automatically without specific configuration by the user or technicians;

- Automatic recognition of input devices: the system should recognize pen drives, CDs and DVDs automatically without additional configuration;

- Support of several media types: the system should support several media types (audio, illustrations, videos, animations) of all common file extensions in the current market;

- The system should support files saved in different operating systems.

Basically, the user interface requirement was leaving the interaction happens in a direct way, avoiding the tasks of accessing menus, folders and subfolders to reach the files or system functionalities. In Figure 9 we can note two user interface views. 


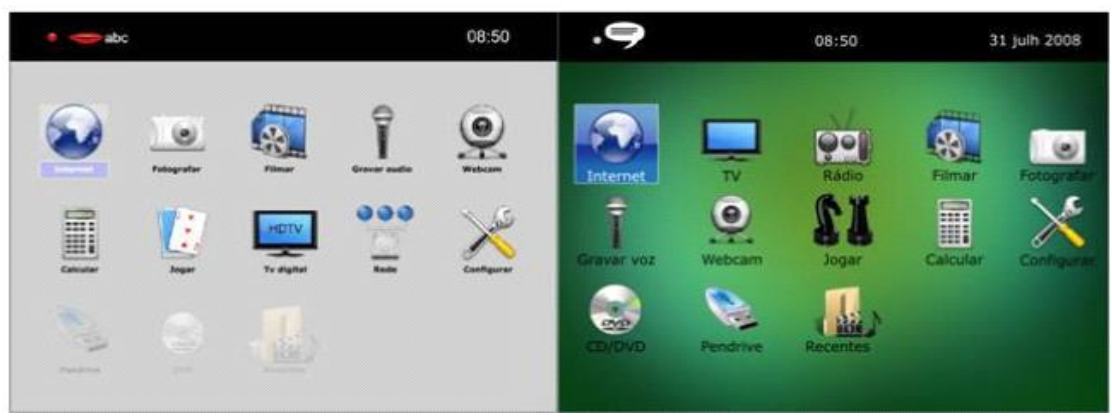

Figure 9: Illustrations of operating system interface.

The operating system user interface was evolved with iterative users' evaluating sessions. All the user interface components and interaction styles were submitted to usability evaluations as described in the next subsections.

\subsection{Task analysis results}

Critical tasks were all modeled and interpreted. They were identified as being part of the critical path from the device initialization to the practical usage, media presentation, web navigation and collective discussion in classroom. In the next images, we can see the task modeled. It's important for the device to be efficient and safe in repetitive and critical tasks like: set up or initiation, finding a media in a flash memory card, navigating on the Internet, taking of the memory card, internal searching medias, excluding a media from the memory card and turning off the device.

Task 1. Lampejo initiation:

Goal: The user must turn Lampejo on.

Selection rule:

If cable is not plugged on the wall Then

connect the plugs correctly

If cable is plugged on the wall Then

turn on the hardware, the projector and wait the system to start.

Method to accomplish Task 1:

Step 1: turn on the hardware

Step 2: turn on the projector

Step 3: wait the system to start

Return with goal accomplished.

Task 2. Introducing flash memory:

Goal: The user must connect a pen drive previously offered and then access its content.

Method to accomplish Task 2:

Step 1: connect the pen drive

Step 2: wait the pen drive icon activation

Step 3: access the pen drive folder

Return with goal accomplished.

Task 2.1. Internal navigation through folders and subfolders:
Goal: The user must navigate through internal folders and sub-folders and access the image file "pendrive.jpg".

Method to accomplish navigating using arrows:

Step 1: swipe in a folder using key ' $>$ '

Step 2: swipe in a folder using key ' $<$ '

Method to accomplish search in all folders:

Step 1: going to the search and filter icon

Step 2: swiping the specific images folder

Method to accomplish navigating folders:

Step 1: finding a nearby folder

Step 2: entering a nearby folder

Step 1: Show the searched image

Return with goal accomplished.

Task 2.2. Flash memory removal:

Goal: The user must close all open files and then remove the pen drive.

Selection rule:

Method to accomplish:

Step 1: close all the files opened

Step 2: close all the folders opened

Step 3: find the flash memory key to be removed

Step 4: entering the flash memory key to be removed

Step 5: removing the pen drive

Return with goal accomplished.

Task 3. Download and save a file in the flash memory:

Goal: The user must access the internet and download a file stored in http://bicarafilm.com/images/medium/shall-wedansu.jpg, then download the file and access it in the 'Recent' folder and save in the pen drive, removing the file from the Recent folder.

Method to accomplish downloading sub-task:

Step 1: finding the Internet icon

Step 2: type the address in the field

Step 3: download the file

Step 4: look for the 'Recent' folder

Step 5: enter the 'Recent' folder

Step 6: choose copy or move the file to the pen drive

Step 7: erase the file in the 'Recent' folder

Return with goal accomplished.

Task 4. Exclude (Remove) file from the flash memory 
card:

Goal: The user must access the 'Recent' menu and search the file, following they must remove and show the file's folder without the file.

Method to accomplish it:

Step 1: access the 'Recent' folder Step 1.1: find the 'Recent' folder

Step 1.2: enter the 'Recent' folder

Step 2: click on the remove bottom

Step 3: show the folder empty

Return with goal accomplished.

Task 5. Turn off Lampejo:

Goal: The user must turn off the device, this task is almost an inverse procedure of the Task 1 .

Method to accomplish it:

Step 1: close all open files in the pen drive

Step 2: close pen drive folder

Step 3: press the remove pen drive key

Step 3.1: wait for permission to remove it

Step 4: Remove pen drive

Return with goal accomplished.

Inspecting all the task structures had showed a very effective performance using Lampejo. It revealed that the initial requirements of the product corresponded to the user's desires for simplicity and the new requirements found in the process were a natural evolution according to our interaction design approach and the initial scope purpose of the project. The fact that the device puts together all multimedia resources in only one device seems to increase the available time for teaching. Evidence to this can the perceived in the speech of this teacher when expressing his point of view:

"I work using it [Lampejo] the most I could. Because it'll allow me more free time, [...]. I'll gain time and the same for the students".

\subsection{Dialogical Analysis: Impact on Teachers' Practice}

The description of teachers' practice using Lampejo in the classroom helped us capture the meanings and interpretations of their use by teachers in a pedagogical action based on their world view, training and professional performance.

In general, these activities involve traditional classes such as Biology, Languages, and Geography among others, in classes composed of a teacher and about 20 students. Exceptionally, one section involving 150 students took place during a special activity in the Brazilian Black Conscious Day, under the supervision of teachers, coordinators and a community leader.
After all events, a careful evaluation and report are presented, evaluating all doubts and difficulties found by teachers during the use of Lampejo. All the analyses helped us suggest new possible changes and improvements in the design and use of Lampejo.

\subsection{Acceptance}

One way to evaluate acceptance is finding indications of teachers' satisfaction and efficiency using Lampejo in their own practice. Analyzing the interviews we could find appreciations on using the equipment from the teachers point of view. One said:

“(...) when Lampejo arrived in our school, we started exploring more resources in the device. Besides the projection capability, features like audio output, USB input, it allowed us bring material from home, ready material prepared at home."

This talk reveals what we expected to produce in terms of efficiency in usage; especially the increase of multimedia usage in the classroom. Collaterally, the planning and presentation practices were restructured.

For teachers, Lampejo itself acts as an artifact that induces positive representations like:

"[it] offers many advantages" and "the device is a revolutionary device inside the teaching practice, in teacher-student and student-teacher relationships".

We believe this positive welcome to Lampejo is due the fact its usage occurs in the classroom and not in a special computer lab filled with traditional computers. In these special rooms, tasks tend to be complex for teachers [16].

\subsection{Effectiveness}

Our original hypothesis was that technologically expert teachers would experience more facility using Lampejo, and novice teacher will need some time to adapt themselves to it considering the simplicity of use.

A teacher comments and expresses the competitive advantage of Lampejo comparing the usage of it in his normal classroom versus the usage in a special computing room at school:

"[...] one classroom fulfilled with computers, it's good. But it's better when we can explore it using projection, when all students are seeing and interacting. The teacher controls the mouse to show this or that images, this is what I'm talking about." 


\subsection{Reflective vision}

The teachers' reflections about the device concept are based on a critical analysis about limits and possibilities of the educational and instructional uses of the new artifact usage inside the classroom, interactively with the students.

\subsection{Convergence}

From the user's point of view, Lampejo represents a device integrating function previous associated to a combination of personal computer, projector and Internet access tool. And, it's seems easy to use in the classroom and to access the Internet. It's a practical tool in the everyday classroom situation but has also proven to be useful in events with more people at school, including teacher formation programs. It seems to be aligned with a recent recommendation about educational technology, that must contribute with "collaboration within colleagues and external specialists to produce new knowledge about the teaching and learning practice." [20, 41, 42]

\section{Discussion}

\subsection{User Centered Design Process}

The interaction design process adopted by the design team showed to be effective to lead in a few iterative cycles to an adequate conceptual model. Conceptualization and evaluation procedures were intercalated. The results of our evaluation produced categories derived from the data analysis. The design and evaluation processes happened in a cycled iterative way based in a full interaction design cycle [12]. Our evaluation cycle consisted of four phases:

1. Gathering user's experiences data in the real context of work

2. Data analyses and interpretations

3. Necessities and requirements

4. Design and Re-design of the conceptual model

We also observed that after three cycles evaluating the requirements lists the project requirements practically stabilized. Teachers were involved in many different roles. And, this was certainly responsible for the fast and effective model convergence. We had professional teachers in the design team, acting as informants and suggesting solutions. We observed another professional teacher working. And, data about practice were presented in workshop meetings and analyzed in collaboration with professional teachers and experienced researchers on the domain.

\subsection{Cultural aspects: The 'most familiar' appearance is not always desired}

Our initial design hypothesis induced us to produce 'familiar' shapes as solutions. We imagined initially that a physical resemblance with electrical devices and ordinary gadgets would be appreciated. As a matter of fact, this hypothesis was not confirmed and familiar aspects perceived in everyday artifacts were finally adapted to the final design. The first prototype designed, a high-fidelity show in Figure 6, has been completely unapproved. Oppositely, the final design model is only similar to a projector device.

\subsection{The emergence of new teaching practice structure and technical abilities}

Using Lampejo in the classroom requires the teacher to adapt and develop new technical abilities to deal with when teaching. This new device structures a new way of teaching in the classroom and even impacting out of the classroom activities like planning, researching for media, and induces for new classroom dynamics for teaching. For technical abilities and competences to deal with computing in the classroom we follow the descriptions proposed by [43] (p. 160-163) the distinction between "know" and "know-how" in using the new technology. So, dealing with Lampejo demands certain knowledge about the functional aspects of its operation that must be learned. Following the task analysis presented before, we can deduce that the abilities to be learned are in general simple.

\subsection{Overcoming fears and other challenges}

To those teachers whom do not master the manipulation of computational devices in their practices, Lampejo can continue to pose a challenge. Negative emotions are evoked in the teachers' discourses like fear and restrictions internalized during long years trying to use any device in the class unfruitful.

From our evaluations the device allows a fluid development of technological capabilities. It can reduce the lack of interaction using digital systems by senior teachers. Those professionals are not in general selfconfident in the use of popular digital devices.

The impressions recorded on this topic suggests that teachers need to become more confident in the use of the system in their daily activities:

"they must let go of the fear, huh!? [sic] Because there are some people who don't come closer to a computer and we see it, that they are afraid of it. And so, we hope that they overcome it and have more contact (with the device). We have done it here: we invite them, only to see the equipment: "came on to know the device!" 
(...) When they come, they see: "ah, it is really... it is easier than a computer...!". It is necessary that they get to know it, have more contact and become more familiar with it".

These challenges to the introduction of information technologies in public school are certainly consequences of what the computational artifact means in the teacher's daily activities. The performance of a teacher in the use of technological devices in the classroom needs to be (re)built with new capabilities which are not approached during their initial formation. It is necessary that a continuous training program brings closer theory about practice with technology and the effective practice involving interactions with the new artifacts. The new design is equally justified.

\subsection{Continually improving the design}

Further investments improving the design of Lampejo depends on the track of its usage in different contexts; conducting observations and evaluation sessions with novice teachers and students. Further studies can help understanding the new challenges to the design and how we can improve the product in order to increase its suitability to the teaching practice.

\section{Conclusions}

In this paper, we have presented the design of Lampejo - a Self-standing Multimedia Enriched Projector. We have presented our design process: from the first brief interpretation to a field study in a real usage context and the first scale distribution. This project contributed to our understanding of how new technologies can be designed to continually engage teachers to innovate in their practice. The device proved to be easy to use in many tasks and effectively contributed transforming the practice in classrooms situation.

About the design process, besides generating a conceptual model based in a set of personal assumptions or guidelines, we could progress in understanding the interactions performed with some prototypes during the conception of our product. We could observe the main interaction possibilities and the main limitations of our concepts and design process.

In so doing, the functional requirements were adjusted during the development of the computational artifact Lampejo, fulfilling teachers needs to achieve their pedagogical objectives in the classroom. Following the Brazilian Norm NBR: "the approach has the advantage that is focused on the real purpose of designing a product - it meets the needs of real users developing real tasks in an organizational, technical, physical and real context". Thus, teachers can develop their pedagogical activities and teaching with the use of Lampejo efficiently, effectively and with satisfaction.

We consider Lampejo an innovation to the classroom conventional culture and teacher practice. Teachers change the way they produce knowledge about computing and about instructional practices, transforming their own practice. Therefore, the computational artifact Lampejo creates a new teaching and learning environment the classroom, in which communication and negotiation phenomena are mediated by image, sound, video, text and internet in an easy and efficient fashion. Lampejo brings opportunities for theoretical and practical situations to students in the classroom. It is also useful to the teacher in their pedagogical practice, in their practice, and to the education system as a resource for continuing training to distance for teachers in all educational levels: federal, state and municipal.

\section{References}

[1] 3M. (2011). 3M $\mathrm{M}^{\mathrm{TM}}$ Standard Electronic Board Stacking Connector, Available at: http://www.3m.com/product/information/StdElectronic-Board-Stacking-Connector.html Accessed on: Dec 2011.

[2] Alcoforado, M. Comunicação intermediada por protótipos. Master Dissertation -Universidade Federal de Pernambuco. CAC. Design, Recife, 2007.

[3] Bielschowsky, C. E. Tecnologia Da Informação E Comunicação Das Escolas Públicas Brasileiras: O Programa Proinfo Integrado. Revista e-curriculum, 5 (1), 2009.

[4] Bruner, J. Acts of Meaning. Cambridge, MA: Harvard University Press, 1990.

[5] Buxton B. Sketching User Experiences: Getting the Design Right and the Right Design. San Francisco: Morgan Kaufmann, 2007.

[6] Buzan T. \& Buzan B. The Mind Map Book: How to Use Radiant Thinking to Maximize Your Brain's Untapped Potential. Conference Eurologo'99: 18-29. New York: Penguin, 2009.

[7] Cooper A., Reimann R., \& Cronin D. About Face 3: The Essentials of Interaction Design. Indianapolis: Wiley Publishing, 2007.

[8] Donnelly D., McGarr O. \& O'Reilly J. A framework for teachers' integration of ICT into their classroom practice, Computers \& Education, 57(2): 1469-1483, 2011. 
[9] Falcão, T.P.R. \& Gomes, A.S. Modelagem de soluções ubíquas para uso em salas de aula do ensino fundamental. Global Congress on Engineering and Technology Education, 2004.

[10] Flick, U. An Introduction to Qualitative Research (3rd ed.). London: Sage Publications, 2006.

[11] Hammersley, M. \& Atkinson, P. Ethnography: principles in practice. London: Routledge, 1995.

[12] Sharp H., Rogers, Y. \& Preece J. Interaction Design: Beyond Human-Computer Interaction. West Sussex, England: John Wiley \& Sons, 2007.

[13] Hoyles, C. \& Noss, R. Playing with (and without) words. Proceedings of the Seventh European Logo i-Pen: Presentation Digital Pen/Optical Pen Mouse. Available at: http://www.zyonshop.com/product/ipen.htm.

Accessed on: Aug 2007.

[14] Tondeur J., van Keer H., van Braak J. \& Valcke M. ICT integration in the classroom: Challenging the potential of a school policy, Computers \& Education, 51(1): 212-223, 2008.

[15] Kujala, S., Kauppinen, M., and Rekola, S. (2001). Bridging the gap between user needs and user requirements. In Avouris, N. \& Fakotakis, N. (eds.), Advances in Human-Computer Interaction I (Proceedings of the Panhellenic. Conference with International Participation in Human-Computer Interaction PC - HCI (2001), pp. 45-50. Typorama Publications

[16] Lins, W.C.B.; Gitirana, V.; Gomes, A.S. Analysis of Teacher's Activity with Educational Software into Computer Laboratory. In: 11th International Conference on Human-Computer Interaction Conference Proceedings, Las Vegas: EDITORA, 2005.

[17] Lobach B. Design Industrial: Bases para a configuração de produtos industriais. LOCAL: Blucher, 2001

[18] Manders, C. \& Farbiz, F. Virtual reality interactions using inexpensive webcams. In Proceedings of the 8th international Conference on Virtual Reality Continuum and Its Applications in industry (Yokohama, Japan, December 14 - 15, 2009). S. N. Spencer, Ed. VRCAI '09. ACM, New York, NY, pp. 339-343, 2009.

[19] Marconi, M.A.; Lakatos, and M. Técnicas de pesquisa: planejamento e execução de pesquisas, amostragens e técnicas de pesquisa, elaboração, análise e interpretação de dados. $7^{\mathrm{a}}$ Ed. São Paulo: Átlas, 2008.

[20] MEB, (2007). Basis Education Movement, "News about literacy - data from Unesco". Available http://www.meb.org.br/noticias/unescoalfabetiza cao. Accessed on: Jun 2007

[21] Brasil, Brazil Ministry of Education, Relatório SAEB 2001. Available at: http://www.inep.gov.br/basica/saeb/. Accessed on: Jan. 2007.

[22] Millen, D.R. Rapid ethnography: Time deepening strategies for HCI field research. In Symposium on Designing Interactive Systems DIS'00, New York. ACM, 2000.

[23] nVIVO.

http://www.qsrinternational.com/products nvivo .aspx Accessed on: Jan 2011.

[24] O'Reilly, T. What Is Web 2.0: Design Patterns and Business Models for the Next Generation of Software. Available at: http://oreilly.com/web2/archive/what-is-web20.html. Accessed on: Jul. 2007.

[25] O'Malley, C. \& Fraser, D. S. Literature Review in Learning with Tangible Technologies. NESTA Futurelab (12), 2004.

[26] Oppenheimer, T. The computer delusion. The Atlantic Monthly, 280 (1): 45-62, 1997.

[27] Panasonic. http://www.panasonic.com/business/office/pro whi.asp Accessed on: Dec 2011.

[28] Polyvision. http://www.polyvision.com/solutions/interactivewhiteboards Accessed on: Dec 2011.

[29] Price, S., Rogers, Y., \& Scaife, M. Using tangibles to promote novel forms of playful learning. Interacting with Computers, 15(2):169185. Special Issue on Interaction Design and Children. 2003.

[30] Proctor, R.M.J., Baturo, A.R., \& Cooper, T.J. Integrating concrete and virtual materials in an elementary mathematics classroom: a case study of success with fractions. In Proceedings of Seventh World Conference on Computers in Education, 8: 87-92, 2001.

[31] Trucano, Michael. 2008. Quick guide to lowcost computing devices and initiatives for the developing world. An infoDev briefing sheet. 
Washington, DC: infoDev / World Bank.

[32] Raffle, H., Parkes, A., \& Ishii, H. Topobo: A constructive assembly system with kinetic memory. In Proceedings of the SIGCHI Conference on Human Factors in Computing Systems (CHI'04), Austria. 2004.

[33] Resnick, M., Maryin, F., Berg, R., Boovoy, R., Colella, V., Kramer, K., et al. Digital manipulatives: new toys to think with. In Proceedings of the SIGCHI Conference on Human Factors in Computing Systems (CHI'98), 281-287, 1998.

[34] Rittel, H. Second-Generation Design Methods, in Developments in Design Methodology. London: John Wiley \& Sons, 1984.

[35] Rosa, M. V. F. P. C., Arnoldi, M. A. G. C. A entrevista na pesquisa qualitativa : mecanismo para validação dos resultados. (1st ed.). Belo Horizonte : Autêntica, 2008.

[36] Ryokai K., Marti S., \& Ishii, H. I/O brush: drawing with everyday objects as ink. In Proceedings of the SIGCHI conference on Human factors in computing systems (CHI '04). ACM, New York, NY, USA, 303-310. DOI $=10.1145 / 985692.985731,2004$.

[37] Scarlatos, L. L., Dushkina, Y. and Landy, S. (1999). TICLE: A tangible interface for collaborative learning environments. In Extended Abstracts of the SIGCHI Conference on Human Factors in Computing Systems (CHI'99): 260-261, USA.

[38] Scarlatos, T. and Scarlatos, L. (2006). Tangible Math Applications. Available at: http://www.cs.sunysb.edu/

tony/research/Math.pdf. Accessed on: Aug. 2006.

[39] Smarttech. 2011., http://smarttech.com/, Accessed on: Feb 2010

[40] Ullmer, B. and Ishii, H. Emerging frameworks for tangible user interfaces. IBM Systems Journal, 39 (3/4): 915-931, 2000.

[41] UNESCO. Available at: http://portal.unesco.org. Accessed on: Feb 2010.

[42] UNESCO. Available at: http://unesco.org. Accessed on: Aug 2007.

[43] Coll, C., Martín, E., Mauri, T., Miras, M., Onrubia, J., Solé, I. e Zabala, A. O construtivismo na sala de aula. São Paulo: Ática, 2006. 